\title{
NOTES
}

\section{Doping of Polyaniline: Mechanism, Captodative Effect, Biochemical Relationships, and Chronology}

\author{
Peter KovaCiC* and Jack W. TimberlaKe** \\ * Department of Chemistry, University of Wisconsin-Milwaukee, \\ Milwaukee, WI 53211, U.S.A. \\ ** Department of Chemistry University of New Orleans, \\ New Orleans, LA 70148, U.S.A.
}

(Received April 13, 1988)

\begin{abstract}
KEY WORDS Polyaniline / Doping Mechanism / Captodative Effect / Biochemical Relationships /
\end{abstract}

Polyaniline, a conducting polymer, has been the object of appreciable activity in the recent past. This communication presents a chronology and brief review of the doping mechanism; reference citations are representative. It is shown that the captodative effect can be applied. Relationships to the biochemical area are discussed.

\section{DISCUSSION}

\section{Mechanism of Doping and Chronology}

The good conducting properties of polyaniline have been known for almost twenty years. ${ }^{1,2}$ Quite often, when there is a renewal of interest, the pioneering work is allowed to fade into the background. It should also be recognized that the early investigators were aware in a general fashion of the theoretical implications. They astutely concluded that both ionic and electronic aspects are involved, and that new approaches to the basic mechanistic features of conduction would be necessary. Furthermore, the authors noted the potential for practical application.

In 1983 the proposal was advanced that the conjugated iminium ion plays an important role in electron transfer processes in vivo involving endogenous and exogenous agents. ${ }^{3 a}$
In our laboratory the concept has been applied to carcinogens, ${ }^{4}$ anticancer agents, ${ }^{5}$ antimalarials, ${ }^{6}$ antibacterials, ${ }^{7}$ antiprotozoan agents, ${ }^{8}$ amebicides, ${ }^{9}$ and benzodiazepines. ${ }^{10}$ It was also pointed out that iminium polymers should comprise an important, novel class from the standpoint of doping mechanism and possible utility. ${ }^{3 b}$

The transformation of conjugated hydrocarbon polymers, such as polyacetylene and poly( $p$-phenylene), to conducting radical cations entails an oxidative process. ${ }^{11}$ The suggestion has been made that a new method of doping to form a radical cation of type 2 could be realized by reduction of the diiminium functionality $1 .^{3 \mathrm{~b}}$ Favorable driving forces<smiles>CC(C)=[N+](C)C</smiles>

1<smiles>CC(N)=[C+]C(C)=[C+]N(C)C</smiles>

2 would comprise electron attraction by the positive charge and delocalization of the resultant reactive intermediate. Various classes of imine polymers, including polyaniline and Schiff bases, were proposed as precursors for the requisite iminium moieties. ${ }^{3 \mathrm{~b}}$ The prediction was made: "Based on the knowledge that 
conducting polymers have attracted considerable attention in recent years, some of these charge transfer structures may be of interest for application in that area."

There has been a surge of research interest in polyaniline starting in about 1984 . This polymer can incorporate various structures such as 3 and 4, depending upon the degree of oxi-

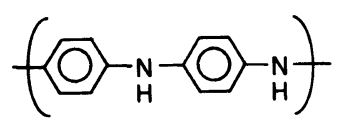

3

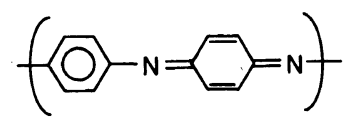

4 dation. ${ }^{12}$ In relation to the mechanism of doping, a number of proposals have been put forth. One entails protonation leading to conduction by the cationic form $5 .^{12}$ The impor-

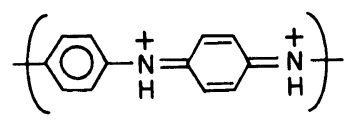

5

tance of $\mathrm{pH}$ control has been demonstrated. ${ }^{12}$ Within the past few years, a consensus ${ }^{13-17}$ seems to be emerging in favor of participation by a quinonediimine radical cation, in accord with the earlier hypothesis. ${ }^{3 b}$ Furthermore, self doping could be achieved by donor-acceptor interaction of $\mathbf{3}$ and $\mathbf{5}$ to give repeating units of the delocalized radical ion. ${ }^{13-17}$ Diiminium is believed to possess a high free energy content and a positive reduction potential. ${ }^{18}$

\section{Captodative Effect}

There is an important energetic feature associated with this reactive intermediate that has apparently not been recognized by those involved. Various investigators have shown that carbon radicals benefit from enhanced stabilization when attached to both an electron-withdrawing and an electron-donating substituent. As a result, the combined influence is greater than the sum of the individual effects. For this concept which was first ad- vanced from a theoretical base, ${ }^{19}$ several descriptive terms have been used: captodative ${ }^{20}$ mero, ${ }^{21}$ and push-pull. ${ }^{22} \mathrm{~A}$ significant contributing resonance form for 2 is 6 . The

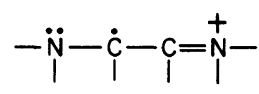

6

amine represents the donating entity, whereas the iminium functionality is a good acceptor. When applied to the polyaniline case, the vinylogous structure 7 , which is also present in<smiles>CN(C)C1C=CC(=[N+](C)C)C=C1</smiles>

7

Wurster salts, would pertain. Interestingly, the non-polymeric structures have been previously presented as illustrations of the captodative effect. $^{20}$

\section{Biochemical Relationships}

Application of the captodative effect can also be made to living systems, as had been predicted by Viehe and co-workers. ${ }^{20}$ Examples closely related to polyaniline will be presented. One case involves the transformation of paraquat (herbicide) to the relatively stable vinylog (8) of 6 by one-electron re-

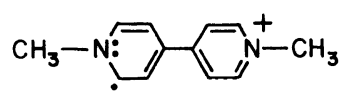

8

\section{duction. $^{23}$}

An analogous situation apparently pertains to the $\beta$-lactams, the most important class of antibiotics. Evidence has recently been presented for an electron transfer (ET) component associated with the mechanism of action, in addition to enzyme inactivation. ${ }^{24}$ 
For the cephalosporin types (9) ( $\mathrm{L}=$ leaving group), the ET entity is a conjugated imine (10) or iminium (11) carboxylic acid formed

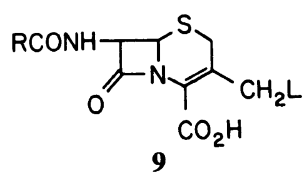

9

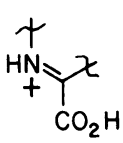

11<smiles>[R]OC(=O)C(NC(=O)OCC)C1N=C(C(=O)O)C(=C)CS1</smiles>

10

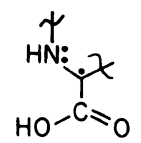

12 as a result of ring opening by enzyme (EOH). ${ }^{24-26}$ Acceptance of an electron and proton in sequence by $\mathbf{1 0}$ would yield the same radical (12) as derived from one-electron reduction of 11 . The radical 12 , related to 6 , would also be stabilized by captodative forces. Electrochemical studies on simple models of $\mathbf{1 0}$ and 11 reveal favorable reduction potentials in the range of -0.3 to $-0.5 \mathrm{~V}$. Evidence shows a substantial enhancement (about $0.5 \mathrm{~V}$ ) in the $E$ value on attachment of carboxyl to iminium. The potentials are of the same magnitude as for well-known ET agents, such as quinones. Chemical replacement of the carboxyl group in $\beta$-lactam antibiotics has not provided derivatives of significant interest, except for the tetrazole nucleus. ${ }^{27}$ The counterpart of $\mathbf{1 2}$ in this case is illustrated by 13 , which is more akin structurally to 6 . If protonation of carboxyl and particularly of the basic tetrazole moiety were to occur at the active site, the capto effect would be enhanced.

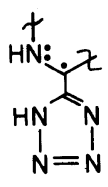

13

The essential flavin enzymes also exemplify the captodative effect as evidenced by the nature of the readily formed, one-electron reduction product $(\mathbf{1 4})^{28}$ which also resembles 6.<smiles>CNC(N(C)C)C(C)(C)C</smiles>

Acknowledgement. I am grateful to the Chemistry Department, University of North Carolina-Chapel Hill, for a visiting professor appointment during the fall semester, 1987.

\section{REFERENCES}

1. R. deSurville, M. Josefowicz, L. T. Yu, J. Perichon, and R. Buvet, Electrochim. Acta, 13, 1451 (1968).

2. M. Jozefowicz, L. T. Yu, J. Perichon, and R. Buvet, J. Polym. Sci. C, 22, 1187 (1969).

3. P. Kovacic, "Fundamental Chemistry of Life and Death," University of Wisconsin-Milwaukee Bookstore, WI, copyright March 1983, (a) pp 1151; (b) pp 18, 86, 87.

4. P. Kovacic, P. W. Crawford, M. D. Ryan, and V. C. Nelson, Bioelectrochem. Bioenerg., 15, 305 (1986).

5. P. Kovacic, J. R. Ames, P. Lumme, H. Elo, O. Cox, H. Jackson, L. A. Rivera, L. Ramirez, and M. D. Ryan, Anti-Cancer Drug Design, 1, 197 (1986).

6. J. R. Ames, M. D. Ryan, D. L. Klayman, and P. Kovacic, J. Free Radicals Biol. Med., 1, 353 (1985).

7. J. R. Ames, M. D. Ryan, and P. Kovacic, J. Free Radicals Biol. Med., 2, 377 (1986).

8. J. R. Ames, M. D. Ryan, and P. Kovacic, Life Sci., 41, 1895 (1987).

9. J. R. Ames, U. Hollstein, A. R. Gagneux, M. D. Ryan, and P. Kovacic, Free Radicals Biol. Med., 3, 85 (1987).

10. P. W. Crawford, P. Kovacic, N. W. Gilman, and M. D. Ryan, Bioelectrochem. Bioenerg., 16, 407 (1986).

11. T. A. Skotheim, Ed., "Handbook of Conducting Polymers," Vols. 1 and 2, Marcel Dekker, New York, N. Y., 1986.

12. J.-C. Chiang and A. MacDiarmid, Syn. Metals, 13, 193 (1986).

13. P. M. McManus, S. C: Yang, and R. J. Cushman, J. Chem. Soc., Chem. Commun., 1556 (1985).

14. G. E. Wnek, Syn. Metals, 15, 213 (1986).

15. A. G. MacDiarmid, J. C. Chiang, A. F. Richter, and A. J. Epstein, Syn. Metals, 18, 285 (1987).

16. T. Hjertberg, M. Sandberg, $O$. Wennerström, and I. Lagerstedt, Syn. Metals, 21, 31 (1987). 
17. F. Wudl, R. O. Angus, Jr., F. L. Lu, P. M. Allemand, D. J. Vachon, M. Nowak, Z. X. Liu, and A. J. Heeger, J. Am. Chem. Soc., 109, 3677 (1987).

18. G. Eberlein and T. Bruice, J. Am. Chem. Soc., 109, 6679 (1983)

19. M. J. S. Dewar, J. Am. Chem. Soc., 74, 3353 (1952).

20. H. G. Viehe, Z. Janousek, R. Merényi, and L. Stella, Acc. Chem. Res., 18, 148 (1985).

21. R. W. Baldock, P. Hudson, A. R. Katritsky, and F. Soti, J. Chem. Soc., Perkin Trans., 1, 1422 (1974).

22. A. T. Balaban, Rev. Roum. Chim., 16, 725 (1971).

23. R. P. Mason, "Free Radicals in Biology," Vol. V, W. A. Pryor, Ed., Academic Press, New York, N. Y., 1982, pp 187-190.
24. P. Kovacic, M. Jawdosiuk, J. R. Ames, and M. D. Ryan, Bioorg. Chem., 15, 423 (1987).

25. P. Kovacic, W. J. Popp, J. W. Timberlake, and M. D. Ryan, Chem.-Biol., Interactions, in press.

26. P. Kovacic, J. R. Ames, and M. D. Ryan, Bioorg. Chem., 16, 149 (1988).

27. J. R. E. Hoover and G. L. Dunn, "Burger's Medicinal Chemistry," Part II, M. E. Wolff, Ed., Wiley, New York, N. Y., 1979, pp 143, 144.

28. D. E. Metzler, "Biochemistry. The Chemical Reactions of Living Cells," Academic Press, New York, N. Y., 1977, pp 483, 484. 